\title{
Una genealogía de las modernas ideologías de la práctica
}

" A genealogy of modern ideologies of practice

Juan Antonio González de Requena Farré

Universidad Austral de Chile, Chile

\section{Resumen}

En el marco ideológico de la autocomprensión moderna, las relaciones entre teoría y praxis se caracterizan por cierta diferenciación funcional y por la interdependencia compleja de sus rendimientos. Sobre ese trasfondo, adquieren una eficacia ideológica tanto los elogios de la teoría como la consagración de la práctica operativa, el oficio profesional o la praxis transformadora. En este artículo, se explicitan los componentes ideológicos de la legitimación de la práctica en el pragmatismo filosófico, la filosofía de la praxis y la filosofía práctica, ya se trate de la nostalgia sacralizadora, la neutralización instrumental o el mesianismo utópico.

Palabras clave: teoría, práctica, profesión, praxis, ideología

\begin{abstract}
In the ideological framework of modern self-understanding, the relations between theory and praxis are characterized by a certain functional differentiation and by the complex interdependence of their performances. On this background, both the praises of theory and the consecration of operational practice, professional office or transforming praxis take on an ideological efficacy. In this article, the ideological components of the legitimation of practice in philosophical pragmatism, the philosophy of praxis and practical philosophy are explained, be it sacralising nostalgia, instrumental neutralization or utopian messianism.
\end{abstract}

Keywords: theory, practice, profession, praxis, ideology

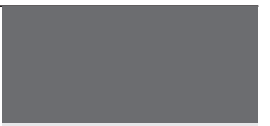

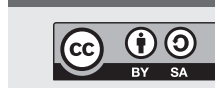

() 2019

\section{Correspondencia de}

autor:

jgonzalez@spm.uach.cl

列

Recibido:

20/Julio/2018

\section{Aceptado:}

20/0ctubre/2018

\section{Publicado:}

3/Enero/2019 


\section{Introducción}

En el escenario intelectual contemporáneo se alternan los elogios de la teoría y las reivindicaciones de la práctica. En cada caso, encontramos un relato distintivo del curso que ha seguido la reorganización de los saberes en el contexto de los procesos de modernización: o bien el relato de un olvido progresivo de la contemplación teorética autónoma que le dio forma espiritual a Occidente; o bien la narración de una hipertrofia de la teoría abstracta y descontextualizada, a expensas de las prácticas locales singulares. Lo que estos alegatos (y sus correspondientes relatos) obliteran sistemáticamente es el trasfondo histórico sobre el cual se redistribuyeron las pretensiones de la teoría y de la práctica, a saber: el paso de la clásica relación jerárquica entre teoría y práctica, a la moderna diferenciación funcional e intercambio cruzado de rendimientos entre sistemas teóricos y entornos prácticos. Sobre ese trasfondo, se comprenden mejor las autoconcepciones de la práctica que se han articulado a través de los procesos de modernización: la práctica como procedimiento pragmático, la práctica como profesión y una praxis sobrecargada con pretensiones emancipatorias. Una genealogía de las formas de autocomprensión moderna de la práctica no solo permite examinar críticamente las perspectivas contingentes, las versiones unilaterales y las expectativas desmedidas que subyacen a ciertas consagraciones de la praxis; además elude la tentación nostálgica de rescatar -en nombre de alguna "filosofía de la praxis"- un sentido de la práctica periclitado, que concibe a la actividad humana como portadora de un saber propio tan circunstancial como moralmente eminente.

\section{Del elogio de la teoría}

La mofa de la teoría (y del teórico que la cultiva) tiene una larga data, que se remonta a los mismísimos orígenes de la actitud teorética. Así lo evidencia cierta anécdota recogida por Platón (2007a, 174a-b) y por Diógenes Laercio (1887, p.36): estando Tales de Mileto concentrado en la contemplación teórica de los cuerpos celestes, cayó a un pozo y, de ese modo, el filósofo suscitó la burla de una criada (o una vieja, en la versión de Diógenes Laercio), quien se regodeó porque aquel que pretendía contemplar lo celestial no era capaz de ver lo que estaba a sus pies. Aristófanes formula una versión escatológica de esta crítica del teórico, cuando -en su ponzoñosa caricatura 
de Sócrates en Las nubes- relata que una simple salamanquesa interrumpió el elevado pensamiento del filósofo, pues arrojó excremento en la boca del boquiabierto contemplador, absorto en la observación del curso de los astros (Aristófanes, 1984, p.55). De ese modo, en el género cómico se destila esa desconfianza hacia la teoría y el teórico, que es propia del sentido común y de la tradición consuetudinaria, y la sospecha se convierte en abierto sarcasmo de la teorización filosófica. En Aristófanes, el linchamiento sarcástico del teorizador se lleva a cabo en nombre del orden establecido, puesto que se ve en el teórico a un simple sofista embaucador que juega con los argumentos, para relativizar las tradiciones consagradas y corromper a jóvenes incautos. Otras veces, -como ocurrirá más tarde en los diálogos de Luciano de Samosata- el filósofo que cultiva la teoría es reprendido (en nombre de la valoración cínica de una vida sincera, sencilla y autosuficiente) hasta por los mismos astros y dioses que el teórico observa meticulosamente, pues se considera que, tras la teoría altisonante, no hay más que vanidad, palabrería, negatividad, hipocresía, así como una profunda inutilidad del teorizador para los asuntos públicos o privados. De ese modo, en los diálogos de Luciano de Samosata, hasta los astros y los dioses - de los que el teorizador abusa pretenciosamente con su palabrería estéril- reclaman que se lleve a cabo de una vez por todas el acallamiento y la aniquilación de los filósofos teoréticos, y abogan por la destrucción y quema de los centros de cultivo de la teoría vana (Luciano de Samosata, 1976, pp.285-294).

Ahora bien, el sarcasmo hacia quienes cultivan la teoría no es sino el reverso (o la inversión paródica) de la consagración de la actividad teorética en el discurso filosófico de la Antigüedad clásica. Al fin y al cabo, la conclusión que se extrae de la anécdota de Tales en el diálogo de Platón es que al filósofo teorizador se le escapan los detalles de la vida cotidiana, así como los asuntos de sus vecinos y prójimos, en la medida en que el pensador privilegia la investigación teórica concerniente a las formas y principios esenciales de las cosas (Platón, 2007a, 174c-175e). Pero no solo el platonismo consagra la vida teórica que se dedica a la contemplación intelectual de las formas puras (o el examen teorético que nos permite remontarnos hasta el verdadero aspecto de las cosas); también Aristóteles privilegia la vida de la contemplación teórica, en la medida en que esta involucra el cultivo de lo más divino que hay en nosotros (el intelecto) y la relación continua con los asuntos intelectuales más relevantes. Así, pues, Aristóteles también considera que la vida teorética constituye 
la más idónea autoperfección de la naturaleza humana, la cual se consuma del mejor modo posible y del modo más autosuficiente a través de la contemplación intelectual desinteresada y despreocupada (Aristóteles, 2000, 1177a- 1178b). En fin, en la filosofía antigua encontramos todo un género de discurso protréptico que despliega una activa defensa de la vida contemplativa y expresa el más alto elogio de la teoría (Gadamer, 1993, p.23).

La labor de autolegitimación de la contemplación filosófica bajo el signo de la teorización pura se sostiene en determinada reinvención semántica del término griego theoros, que en la Grecia antigua designa a cierto tipo de testigo -un delegado oficial-que, tras observar los juegos atléticos 0 atender a los mensajes del oráculo, retornaba a la comunidad para poner en conocimiento a la polis (Kennedy, 1997, pp. 27-29). En ese sentido, la figura pre-filosófica del theoros aparece signada con una serie de características -como la realización de un viaje fuera de la comunidad, la observación cuidadosa de una escena o espectáculo, o la atención dedicada a los designios de los dioses- que serían analógicamente extrapoladas a la tarea del pensador filosófico. De ese modo, la incipiente labor de la contemplación filosófica se recubre con el prestigio tradicional del theoros, para así congraciarse con las creencias intelectuales consolidadas y lograr un reconocimiento de su legitimidad en el contexto de la polis (Wilson Nightingale, 2004). Por analogía con el theoros tradicional, quienes cultivan la teorización filosófica se autocomprenden como viajeros que cruzan los límites intelectuales constrictivos, trascienden esas fronteras desde la perspectiva de lo universal, y retornan para dar cuenta del verdadero aspecto de las cosas a sus conciudadanos. Asimismo, la teoría filosófica se concebirá como el acto de visión de un espectador capaz de remontarse al punto de vista en que se contemplan las formas puras y la esencia de las cosas. Y, como se aprecia en algunos elogios de la teoría filosófica, la preeminencia de la labor de este nuevo theoros filosófico se justifica tanto por el asunto divino de que el pensador se hace cargo (el orden último del ser y la unidad esencial de lo múltiple) cuanto por la semejanza de la contemplación intelectual con la autosuficiencia divina (en particular, con ese dios aristotélico que, como motor inmóvil, se dedica a la pura autocontemplación).

Así, pues, la autoinvestidura de la contemplación filosófica como theoría no depende únicamente del nuevo tipo de discurso visual, analítico y abstracto -basado en un acto de visión distanciada del texto-, que se consolidó a raíz de la revolución 
alfabética en la antigua Grecia (con la difusión de la tecnología intelectual de la escritura y con el desplazamiento desde la narrativa oral de prácticas situacionales hasta la teorización temática de conceptos abstractos) (Havelock, 2002, pp. 235-248). La autopresentación del pensamiento filosófico como theoría responde a cierta necesidad de legitimación social -bajo un léxico tradicional respetable- de los nuevos hábitos y oficios intelectuales que se desarrollaban en la polis griega. En semejante contexto de redistribución del trabajo intelectual y de los campos de estudio, así como en el marco de la institucionalización progresiva de la enseñanza intelectual en torno a centros de pensamiento establecidos (como la Academia platónica o el Liceo aristotélico), vemos erigirse las pretensiones de saber de una nueva aristocracia intelectual que -como heredera del rol tradicional del theorosreclama reconocimiento en la comunidad (Wilson Nightingale, 2004, pp. 1-29).

Curiosamente, los elogios de la teoría no son exclusivos del mundo antiguo y tienen cierta continuidad en la filosofía contemporánea. En ese sentido, Husserl (1998) vincula la estructura intelectual europea al despliegue de una actitud teórica que pone entre paréntesis la praxis natural y los intereses cotidianos (e, incluso, la ciencia objetivista), para asumir una vocación compartida y una tarea infinita, a saber: la visión universal y la contemplación del mundo como espectadores desinteresados, consagrados a la ampliación ilimitada del conocimiento teórico y a la teorización espiritual autónoma, o sea a la filosofía. Y es que - para Husserl- la crisis espiritual europea, asociada al fracaso de un racionalismo tan enajenado como atrapado en el naturalismo objetivista, solo encuentra cierto horizonte de superación si asume como tarea infinita la teorización universal y la autonomía espiritual de la filosofía (Husserl, 1998, pp.75-128).

También encontramos cierto elogio de la teoría en la contemporánea hermenéutica filosófica. Aunque Heidegger consideró que la reflexión temática y la visión teórica resultan derivados con respecto a la familiaridad práctica absorta de nuestra comprensión cotidiana, también ha insistido en la urgencia de una meditación o cuestionamiento decisivo sobre la esencia de la verdad y del ente, que se haga cargo de lo incalculable de nuestro ser en el mundo (ese estar entre el ocultamiento y el desocultamiento del ser de lo que hay). Solo así se puede hacer frente a esa deriva de la investigación científica moderna, en la cual lo único que se proyecta es la planificación anticipada, la representación objetivadora y la disposición calcu- 
lable de la totalidad de lo existente, para asegurar su control tecnológico (Heidegger, 1960). Según Heidegger, el sentido de la theoría griega (atender con admiración al espectáculo de la manifestación y desocultamiento de lo presente en su verdad), habría derivado en la contemplatio latina, o sea en un observar que acota, y en un proceder divisor que persigue capturar lo que hay al inspeccionarlo. En el caso de la investigación científica moderna, la teorización se convierte finalmente en un mero proyectar planificado y en una elaboración representadora, al servicio del aseguramiento y control de un mundo tan objetivado como calculable (Heidegger, 1997, pp.152-166). Por su parte, Gadamer elogiará la actitud teorética como un modo de contemplación involucrada que, si bien se despliega como un ver puro y desinteresado, permanece volcada y entregada a algo otro que la trasciende y de lo cual no puede apoderarse. En ese sentido, la theoría que Gadamer elogia como vía formativa no consiste en la mera observación informada o en la inspección objetivadora, pero tampoco se identifica con la búsqueda de esa autoconciencia que tanto ha privilegiado el saber moderno, esto es, el autoaseguramiento del sujeto cognoscente contrapuesto a un mundo objetivado (Gadamer, 1993, pp.23-43).

En fin, encontramos elogios contemporáneos de la teoría, con frecuencia marcados por un tono entre trágico y nostálgico. Con un tono bastante acongojado, Giovanni Reale ha querido ver en el declive actual de la contemplación teórica una de las máscaras nihilistas que recubren la desorientación de nuestra época. De acuerdo a Reale (1996), el productivismo y el pragmatismo consagran la premisa de que es verdadero lo que puede hacerse, de manera que todo lo existente se pondría al servicio de la utilidad ejecutable en el dispositivo técnico. De ahí que, bajo cierta nostalgia de la theoría antigua, se apele a un rescate de la profundidad ontológica de la contemplación teórica; solo mediante la actitud teórica contemplativa, que nos abre a la verdad trascendente del ser, podríamos trascender la mentalidad "tecnomorfa" y la extralimitada voluntad de control tecnológico (Reale, 1996, pp.81-94).

Ahora bien, en el pensamiento filosófico de la Antigüedad (tanto en Platón como en Aristóteles) el elogio de la teorización pura no involucraba una denegación o cuestionamiento polémico del saber aplicado y práctico. No en vano, Platón sostiene la unidad del saber verdadero, cuyo conjunto comprende tanto el saber puramente cognoscitivo, cuanto el saber práctico o aplicado en la producción y en la acción (Platón, 2007b, 258d-e). De ahí que frecuentemente aparezcan en Platón caracteri- 
zaciones del saber que se sirven de la analogía de alguna tejné, esto es del universo de las artes y los oficios, en la medida en que este proporciona modelos de actividad inteligente e intencional (un tipo de símil técnico o productivo que, por lo demás, era muy frecuente en el pensamiento filosófico y científico de la antigua Grecia)(Lloyd, 1987, pp.255-275). De la misma manera, Aristóteles reconoce que tanto la ciencia (episteme), como el arte productivo (tejné) o la deliberación práctica (frónesis), involucran un saber y, por ende, verdad y logos, explicación y justificación a partir de principios explicitables; aunque, - para Aristóteles (2000)- en el caso de la episteme, se trata de un saber demostrativo de lo universal y necesario, y en la tejné o la frónesis, de un saber de lo contingente y particular. De ese modo, la unidad del saber no resulta desmentida por la distinción jerárquica entre los modos de saber, según su alcance teórico, la universalidad y explicitud de sus principios o la importancia y perfección de su asunto. Hay saber en la producción o la acción, aunque el más excelso saber sea la teorización pura que concierne a los principios más eminentes, universales y necesarios, así como a lo más eterno, inmóvil e independiente (Aristóteles, 2000, 1139a-1143b).

En ese sentido, cabe reconocer en la concepción del saber de la filosofía clásica ese tipo de configuración ideológica jerárquica que Louis Dumont considera propio de las formas de vida pre-modernas. En la representación jerárquica, existe una unidad comprehensiva y segmentada del saber (así como del ser y de los valores), de manera que las esferas más eminentes del saber engloban a las que se les subordinan. Por otra parte, las esferas de saber subordinadas pueden invertir la jerarquía en algún respecto. Por ejemplo, el saber puro de la teoría engloba al saber práctico, en virtud de la pureza de la contemplación teórica y de la trascendencia de su asunto y la perfección de su actividad; sin embargo, el saber práctico precede a la sabiduría teórica (comprendida, así, como un tipo de virtud intelectual), en lo que respecta a la consideración del bien y a la decisión de lo que resulta mejor para nosotros contingentemente. Pero, ¿en qué se diferencia la jerarquización pre-moderna del saber, de la ideología de los modernos? Según Dumont, la contrapartida moderna de la ideología jerárquica nivela y atomiza las formas del saber (escindidas de las formas del ser y de los valores), de manera que no se pueden reconocer ni englobar las diferencias, y solo queda la simplicidad del conflicto entre saberes particulares y perspectivas individuales (Dumont, 1987, pp.239-275). Por nuestra parte, podríamos 
añadir que la configuración ideológica moderna también introduce una tensión conflictiva entre teoría y práctica, las cuales tan pronto se igualan y superponen (en las exigencias de una ciencia aplicada o de un arte productivo científico), como se confrontan en virtud de su punto de vista, funciones y rendimientos específicos.

Ciertamente, la transición de la jerarquización pre-moderna del saber a la ideología moderna no tuvo lugar de golpe. Ya en el mundo antiguo -como argumenta Jaeger (1992) - se aprecian ciertos desplazamientos en la comprensión de la relación entre el saber teórico y el saber práctico, que apuntan a la agudización de la tensión entre la vida teorética y la actividad práctica. En la filosofía socrática y platónica, el saber moral resulta indiscernible del conocimiento filosófico, y en el pensamiento aristotélico la actividad teorética sigue coronando las formas de la actividad, como la modalidad más eminente y autosuficiente de actividad. Pero, progresivamente, el ideal teorético de vida se opone a la vida práctica, de modo que -como ocurre en el pensamiento de Dicearco de Mesina- se comenzará a privilegiar la sabiduría práctica sobre la simple ciencia y, eventualmente, -por ejemplo, en Filón de Alejandríaasistiremos a un repliegue de la vida teorética bajo la forma religiosa de la vida contemplativa y el ideal de vida monástico (Jaeger, 1992, pp.467-515). En ese sentido esa valoración antigua de la forma de vida filosófica y de la contemplación teorética (como un modo de lograr serenidad espiritual, libertad interior y consciencia de un orden trascendente), que perduró hasta la filosofía helenística y romana, dio paso en el Medievo a una subordinación de la teorización filosófica a la vida monacal (Hadot, 2006, pp.235-249).

Las interpretaciones contemporáneas de la deriva intelectual de la modernidad han enfatizado frecuentemente el carácter instrumental del nexo que, en la investigación científica moderna, se establece entre teoría y práctica. Desde la perspectiva de la teoría crítica, Max Horkheimer formuló cierta versión canónica de la dialéctica intelectual desarrollada en la llustración: la razón moderna se habría desvinculado de toda forma de contemplación teórica de fines trascendentes, para dar paso a una concepción meramente instrumental y subjetiva de la racionalidad, en que esta deviene un simple instrumento de cálculo al servicio de la autoconservación del sujeto. Como plantea Horkheimer (1969), la razón objetiva de los sistemas filosóficos antiguos hacía posible una contemplación intelectual de la totalidad de lo existente como un sistema jerárquico armonioso y una ordenación objetiva de 
la que se desprendía un designio universal. Sin embargo, en virtud de la dialéctica de la llustración, la razón objetiva resulta liquidada, y se transforma en un tipo de racionalidad calculadora e instrumental, que tan solo dispone medios y procedimientos eficientes, sin preocuparse de la racionalidad de los fines. Así, pues, según Horkheimer, la modernidad generó -en nombre de la secularización- una neutralización de la razón frente a todo compromiso espiritual trascendente y todo horizonte de sentido ético o religioso. De esa manera, la razón se ve despojada de todo sentido de trascendencia y de toda objetividad, y se desintegra la autonomía intelectual; al fin y al cabo, la razón subjetiva e instrumental también es una razón formalista, que reduce la labor intelectual a la acomodación técnica de datos fácticos y la sistematización esquemática de todo lo singular (Horkheimer, 1969, pp.15-68). En ese sentido Horkheimer (2003) considera que la concepción establecida de la teoría -que surge a partir de cierta autoconciencia ilusoria de la autonomía de la labor intelectual científica, en el conjunto de la división social del trabajo- se limita a caracterizar la subsunción sistemática universal de lo dado, bajo el aparato conceptual de la ciencia y la formalización deductiva, así como enfatiza la aplicación instrumental de hipótesis a través del procedimiento experimental. Frente a esta obtusa e ideológica autoconcepción de la teoría establecida, Horkheimer apelaba a un ejercicio crítico de la teorización, que fuera capaz de comprender su nexo con el trasfondo de las prácticas sociales y apostar por una praxis transformadora (Horkheimer, 2003, pp. 247-254).

También Hans Jonas - desde las premisas de una ética de la responsabilidad, la cual apela a hacerse cargo de las consecuencias impensadas de la intervención tecno-científica- reconoce que en la investigación científica moderna existe un nexo interno entre teoría y aplicación tecnológica instrumental. En ese sentido, la ciencia moderna se distingue del ideal antiguo de teoría pura, que se consagraba a los fines más eminentes en la jerarquía del ser y del saber, esto es, a la relación con una trascendencia objetiva y a la contemplación intelectual entregada a la meditación reverente de la verdad del ser. Según Jonas, la teoría de la ciencia natural consiste internamente en un hacer tecnológico y en un modificar el mundo, del mismo modo que el hacer práctico está al servicio de la acumulación de conocimientos teóricos, tal y como se evidencia en la aplicación del método experimental. En otros términos, en la investigación científica moderna la construcción intelectual 
de modelos tiene intrínsecamente implicaciones tecnológicas, y los procedimientos de intervención guían la teorización. Esto es, la teoría y los resultados prácticos se relacionan funcionalmente, y se retroalimentan instrumentalmente en un ciclo interminable, de manera que la aplicación de la teoría científica genera cuestiones teóricas y las aplicaciones de la teoría se traducen en resultados prácticos. Sin embargo, - para Jonas - ni la teoría de la ciencia pura ni la teorización hipotética de la ciencia aplicada pueden reemplazar al juicio práctico que ha de tomar decisiones concretas relativas a asuntos éticos o políticos (Jonas, 2000, pp.260-277). En ese sentido, resulta necesario un saber ético de la previsión y la responsabilidad, que asuma los incalculables riesgos que se desprenden de la tecno-ciencia contemporánea, toda vez que esta ha convertido al propio sujeto humano en parte del dispositivo tecnológico y, a través de la movilización tecnológica ilimitada, ha desbordado incluso la distinción entre tejné y praxis, entre la construcción artificial y el universo práctico de la acción moral (Jonas, 1995, pp.29-38).

Existe una versión diferente de la reorganización intelectual que acaeció en la modernidad, según la cual la Revolución científica -y el marco del pensamiento moderno que la hizo posible- no significó tanto un abandono pragmatista y productivista de la teoría cuanto la generalización desmedida de la teorización abstracta. En su reconstrucción de los trasfondos intelectuales de la modernidad, Stephen Toulmin sostiene que, en la primera modernidad del humanismo renacentista y hasta la primera mitad del siglo XVII, existía una particular preocupación por los asuntos concretos, particulares y circunstanciales de los que se hace cargo el saber práctico. Al fin y al cabo, hasta la Edad Media y, especialmente, con la recuperación de la retórica y la filosofía antiguas por parte del humanismo renacentista, los argumentos se consideraban manifestaciones públicas retóricamente dirigidas a auditorios circunstanciales que compartían tradiciones locales; del mismo modo, la discusión de las cuestiones morales se basaba en casos y antecedentes concretos (Toulmin, 2001, pp.50-78). Sin embargo, la reconstrucción del orden intelectual moderno -sobre el trasfondo de las guerras religiosas y del desarrollo de la Revolución científica- involucró un abandono de los asuntos concretos y circunstanciales de la filosofía práctica, así como impulsó un marcado giro hacia la teoría, esto es, hacia las disquisiciones abstractas y atemporales sobre asuntos generales abordados desde una perspectiva tan universal como impersonal y descontextualizada (Toulmin, 2001, pp.259-267). 
En ese orden de ideas, se podría argumentar que la deriva hacia la teoría descontextualizada resulta inseparable del nuevo nexo funcional entre teoría y práctica en la investigación científica moderna, de manera que -en la modernidad-asistiríamos tanto a cierta recontextualización teórica de las prácticas (que las transforma en procedimientos explicitables y replicables trans-contextualmente) cuanto a determinada operacionalización de la teoría (que hace, de la teorización, una anticipación de consecuencias aplicables y técnicamente reproducibles). No obstante, la versión que Toulmin entrega de la reconstrucción intelectual moderna no concluye precisamente con un elogio de la teoría pura 0 a la contemplación intelectual desinteresada (y no instrumental), sino que apela al hecho de que, tras la Segunda Guerra Mundial, se está llevando a cabo un rescate de la filosofía práctica en el pensamiento contemporáneo.

En cualquier caso, la actual nostalgia de una teorización tan pura como eminente se presenta como un sospechoso intento de autojustificación polémica de un modo de actividad intelectual privilegiado, que -bajo la moderna fragmentación ideológica y en el marco de la actual división funcional del quehacer intelectualya no se encuentra en condiciones de suministrar principios y fines últimos (o una legítima cobertura jerárquica) al resto de perspectivas intelectuales y prácticas. En ese sentido, topamos con la ilusión escolástica que Bourdieu (1999) ha criticado: esa disposición pura a retirarse del mundo para contemplarlo teóricamente, verlo con desapego y pensarlo desde la perspectiva de la eternidad y la universalidad. Sin embargo, semejante disposición escolástica vela ideológicamente sus propios presupuestos mundanos; no solo lleva a cabo cierta neutralización de la diferencia de razones, saberes y prácticas de los actores, sino que, además, consagra la ignorancia y represión de las condiciones socio-económicas (así como de la clausura de los campos académicos) que hacen posible el desapego intelectual de la teorización pura. Claro que, según Bourdieu, este desconocimiento ideológico de los trasfondos prácticos, socioeconómicos y escolásticos se compensa con la ilusión epistémica de una fundamentación teórica última de los restantes saberes o del carácter absolutamente universal $-y$, por ende, universalmente accesible- del punto de vista del intelectual (Bourdieu, 1999, pp.26-61). 


\section{Hacia la consagración de las prácticas}

Las mismas transformaciones intelectuales modernas que se tradujeron en una nueva diferenciación funcional e instrumental (y no jerárquica) entre los roles de la teoría y la práctica, no solo han acarreado altisonantes elogios de la teoría, sino que, además, han introducido de rebote una apasionada invocación del sentido práctico, frente a las pretensiones de la teorización abstracta. Pero lo llamativo de esta moderna consagración de la práctica radica en que, al no presuponer ningún marco de subordinación o englobamiento jerárquicos, no puede llevarse a cabo bajo la forma de una inversión que establezca la primacía de la práctica sobre el saber teórico en algunos aspectos específicos. La apelación contemporánea a la práctica se ejerce desde la premisa tácita de la independencia de perspectivas, la equivalencia funcional y la interacción instrumental entre los puntos de vista de la teoría y las operaciones de la práctica. En ese sentido, la actual reivindicación de la práctica se lleva a cabo frecuentemente contra la perspectiva de la teoría, como una pretensión antagónica de reconocimiento del quehacer práctico, que, sin embargo, no puede dejar de representarse bajo el aspecto de una teoría de la práctica e, incluso, de cierta visión salvífica de la actividad. En ese sentido, el llamado a rescatar el sentido de la práctica puede resultar tan ideológico como el más acusado de los teoricismos, y se traduce habitualmente en alguna ideología de la práctica; pero no se limita a consagrar las ideologías prácticas espontáneas que le dan sentido a las actividades cotidianas, sino que además introduce una representación sinóptica 0 una totalización translaticia del entramado de las prácticas.

En efecto, la reivindicación de la práctica por parte del pragmatismo filosófico presupone una ideología determinada de la práctica, en que esta se perfila como cierta forma de actividad autocorrectiva que apunta a la constante mejora del quehacer humano. Se trata, pues, de una autocomprensión ideológica de la práctica, marcadamente instrumental y meliorista, que contempla la progresiva salvación del mundo a través de la reforma operacional. Como se puede apreciar en las reflexiones teóricas de William James, el pragmatismo no se autopresenta como una doctrina, sino como un método de resolución de nuestras disputas intelectuales, por medio de la consideración de las diferencias prácticas que se siguen de cada planteamiento. Desde esa perspectiva procedimental, las ideas son concebidas únicamente como 
reglas de acción, y las teorías, como instrumentos de intervención y planes operacionales; por otra parte, la verdad se perfila como una operación de verificación y organización de nuestras creencias, y se privilegia el propósito práctico utilitario de nuestras construcciones intelectuales, al alero de una apuesta tan humanista como pluralista (James, 1984). Ciertamente, el pragmatismo filosófico cobró consciencia de las diferencias de significado esbozadas en la concepción pragmatista de la práctica, ya que lo práctico remite tanto a las actitudes y conductas que se asumen frente a un asunto, como a la eficacia de una idea para modificar la situación, o a la importancia y el carácter deseable de algunos fines (Dewey, 2010). Sin embargo, la filosofía pragmatista mantuvo una concepción instrumental comprehensiva, tanto de la teoría, como de las pretensiones e implicaciones prácticas que se obran en una situación concreta, puestas al servicio de la reorganización activa y metódica del medio circundante, pero también subordinadas a la finalidad de resolver los conflictos morales e intelectuales, para propiciar así el desarrollo humano, la reforma social y la felicidad ordenada (Dewey, 1986). A pesar de la autoinvestidura aparentemente procedimental de la práctica (que parece apelar tan solo a una actividad autocorrectiva guiada por la simple aplicación metódica de la intervención operacional eficiente), el pragmatismo filosófico encierra un núcleo ideológico doctrinal; tiende a totalizar la diferencia de sentido de las prácticas e, incluso, consagra cierta doctrina de salvación meliorista. Al fin y al cabo, el propio James no dudó en calificar al pragmatismo como una traslación de sede de la autoridad o como un "protestantismo filosófico" (James, 1984, p.112).

Por lo demás, la visión pragmatista de las ideas como guías de acción y la autocomprensión instrumentalista de la práctica como actividad autocorrectiva o procedimiento metódico constituyen apuestas intelectuales ideológicamente funcionales al escenario desarrollista y reformista que se desarrolló en los Estados Unidos, entre el final de la Guerra de Secesión y las primeras décadas del siglo XX. En efecto, la Guerra Civil había dejado la enseñanza de que los principios abstractos constituyen la antesala de la violencia social; como contrapartida, el pluralismo humanista de los pragmatistas sustentaba una legitimación ideológica de la convivencia democrática y representaba cierta victoria intelectual del unionismo. Por otra parte, el meliorismo pragmatista se consolidó intelectualmente en el momento en que el capitalismo norteamericano se distanciaba del individualismo de la libre competencia, y 
emprendía la vía de la gestión corporativa, la regulación pública y la reforma política (Menand, 2002, pp. 376-379 y 444).

La conexión establecida por James entre pragmatismo y protestantismo podría entenderse como algo más que una analogía entre el desplazamiento de la autoridad religiosa y el cuestionamiento del intelectualismo racionalista. Si seguimos los planteamientos de Weber, hay todo un trasfondo salvífico y cierta ética social de inspiración religiosa detrás de la moderna consagración de la actividad humana en el mundo como una conducta metódica, racional y sistemática, encaminada a realizar con su obra los intereses prácticos, y orientada a maximizar la utilidad social y la prosperidad en los negocios mundanos. En efecto, la ética protestante no solo impulsó una estimación del trabajo ascético intramundano cotidiano como vía de salvación y fin en sí mismo; además, hizo de la profesión algo más que una vocación religiosa ultraterrenal o una misión divina, para transformarla en un imperativo ascético cotidiano y profano: el cumplimiento en este mundo de las actividades productivas que a cada cual le depara su posición económica en la vida (Weber, 1984). En fin, la moderna consagración de la práctica como actividad metódica y la valoración del trabajo profesional como un imperativo ético absoluto hunden sus raíces en cierta concepción religiosa de la profesión, ligada al protestantismo ascético, que -según Weber- hizo posible la formación del espíritu capitalista. No se puede desconocer, pues, que detrás de los actuales llamados al profesionalismo y a la ética profesional se encuentra cierto núcleo ideológico salvífico, que convierte en un fin en sí mismo al trabajo competente y a la obra sistemáticamente productiva. En ese sentido, cuando la práctica se autopresenta como profesión cotidiana eficiente y éticamente regulada, asume ideológicamente una investidura salvífica, por más intramundana y racionalizada que parezca ser su obra.

En otras ocasiones, la consagración contemporánea de la práctica parece desbordar el guion salvífico del meliorismo instrumental o del reformismo metódico, para abrazar una versión veladamente mesiánica de las posibilidades de transformación revolucionaria vinculadas a la praxis humana. Desde que Marx señaló -en sus Tesis sobre Feuerbach- la insuficiencia de la actitud teórica y del pensamiento abstracto, y apeló a asumir la importancia de la transformación revolucionaria y de la actividad práctica crítica, se ha esbozado toda una apuesta por desarrollar una filosofía de la praxis (que, más allá de la tradición marxista, también convoca a ciertos cultores 
de las ciencias sociales críticas). En efecto, Marx (1985) sostuvo que los problemas teóricos desvinculados devienen escolástica vana, y consideró que la validez del pensamiento no se decide simplemente en la crítica teórica, sino que depende de la transformación práctica y de la autocomprensión de la práctica revolucionaria. No es de extrañar que en la versión del marxismo propuesta por Antonio Labriola el materialismo histórico se identificara con una filosofía de la praxis, la cual parte de la práctica concreta del hombre histórico, esto es de la actividad laboriosa que hace posible la transformación de la situación histórica, pero también la metódica elaboración intelectual de esa creación práctica en acto. En la perspectiva de la filosofía de la práctica de Labriola, el proceso de la praxis y de su autocomprensión histórica concreta permite superar la oposición burda entre teoría y práctica; al fin y al cabo, el pensamiento es elaboración productiva (conocer haciendo), del mismo modo que el proceso práctico de la historia en acto requiere de la labor de la crítica (Labriola, 1969).

Posteriormente, Antonio Gramsci formuló toda una filosofía de la praxis que vincula la actividad histórica transformadora con la conciencia crítica de la historicidad y la autocomprensión de la historia en acto. Así, pues, la filosofía de la praxis de Gramsci también concibe cierta unidad de teoría y práctica, vínculo que no es automático, sino que se basa en la autoconciencia crítica políticamente decidida e históricamente autocomprendida. En ese sentido, la labor filosófica no consiste - para Gramsci (1986) - en un simple ejercicio de interpretación teórica coherente, pues lo que está en juego es una lucha cultural contra el sentido común y contra el bloque intelectual-moral hegemónico; se trata de realizar concretamente una nueva autocomprensión histórico-filosófica. Por otra parte, la actividad transformadora de la praxis es eminentemente política, ya que consiste en una labor polémica de dirección consciente y formación crítica de nuevos bloques y hegemonías históricas (Gramsci, 1986).

Sin embargo, bajo la pretensión de la filosofía de la praxis de impugnar la ideología hegemónica y hacer de la teorización filosófica un ejercicio de lucha política, sigue haciéndose presente cierta investidura ideológica de la práctica como creación en acto de nuevas formaciones sociales. No en vano, la filosofía de la praxis lleva a cabo cierta nivelación ideológica -en el todo histórico o en la praxis histórica general- de la diferencia de las prácticas teóricas, las prácticas científicas, las prácticas ideoló- 
gicas y los distintos tipos de actividad histórica. De esa manera, en la filosofía de la praxis se esboza cierta autoconciencia ideológica, tan idealista como voluntarista, que deposita la esperanza del cambio histórico en una autocomprensión filosófica de la historia en acto, así como en la decisión política de luchar contra el bloque histórico hegemónico (Althusser, 1974, pp.130-156).

¿Es posible excluir el elemento utópico y voluntarista de la filosofía de la praxis, tal como ha pretendido cierto marxismo "científico"? Lo cierto es que, en términos generales, el marxismo ocupó un nicho intelectual bastante ambiguo entre finales del siglo XIX y las primeras décadas del siglo XX; surge en un momento en que la religión establecida perdía arrastre cultural en 0ccidente, particularmente entre la clase trabajadora, y cuando los procesos de modernización generaban una marcada fragmentación intelectual, en virtud de la cual ni la ciencia ni el Estado podían suministrar cierta integración cultural. En ese sentido, el marxismo conjuga desde su origen perspectivas ideológicas de la cultura científica decimonónica (el materialismo, la búsqueda de leyes universales, cierto evolucionismo), de la creencia religiosa (la promesa mesiánica y el catastrofismo utópico) e, incluso, del marco político-ideológico del Estado (que tan pronto se consideró un instrumento de opresión capitalista prescindible en una sociedad sin clases, cuanto se entendió como un aparato relativamente autónomo del que servirse revolucionariamente)(Gouldner, 1983, pp. 127-135). Así, pues, incluso en algunas de las versiones más "científicas" del marxismo cabe reconocer un catastrofismo mesiánico latente, que introduce la promesa de una revolución inevitable y de una trascendencia salvífica de las contradicciones del presente. Desde ese punto de vista, el anti-voluntarismo de algunas tradiciones del marxismo -que apelan a una explicación científica de las leyes de la producción capitalista y a una descripción de las estructuras determinantes de los modos de producción social- no consigue desembarazarse ideológicamente del voluntarismo y del utopismo mesiánico, al apelar a una redención revolucionaria tan inminente como inevitable (Gouldner, 1983, pp.219-222).

Podría pensarse - con Hannah Arendt (2005)- que la nivelación ideológica de todas las formas de actividad humana en un concepto genérico de praxis productiva constituye un resultado de cierta inversión de la jerarquía tradicional entre la acción y la contemplación teórica. En virtud de la inversión moderna, la actividad, reducida a la necesidad del trabajo productivo, decide el sentido de la condición humana, en 
una sociedad del trabajo en la que solo resulta significativo aquello que se puede construir metódicamente o fabricar artificialmente. En ese sentido, Hannah Arendt considera que la modernidad ha desdibujado la diferencia entre el saber práctico-político y el conocimiento científico-tecnológico. Pero la moderna reivindicación de la vida activa llevó a cabo una segunda inversión, en virtud de la cual se privilegió la condición del homo faber o del animal laborans, siempre a expensas de la acción, la única forma de vida activa que hace posible que se manifieste de modo eminente la iniciativa de la pluralidad de los hombres. Tanto el trabajo (o sea la producción instrumental de un entorno artificial basado en relaciones instrumentales entre medios eficientes) como la labor (que garantiza la adaptación funcional al proceso de reproducción de la vida y la satisfacción de las necesidades) han suplantado el sentido de la acción compartida, gracias a la cual el hombre consigue distinguirse de otros y comunicarse con los demás, tomar la iniciativa y manifestar su unicidad en el seno de la pluralidad de los hombres (Arendt, 2005, pp.320-349). De esa manera, Hannah Arendt intenta recuperar cierta concepción clásica de la praxis humana y de la acción política, con claras resonancias greco-latinas y particularmente aristotélicas. No en vano, la inversión moderna -o sea la subsunción de la acción bajo el trabajo o la labor-se tradujo en una cada vez más profunda alienación, que es tanto una pérdida de sentido y un extrañamiento del mundo, cuanto una carencia de iniciativa. En fin, la iniciativa de la praxis se pierde en el seno de un gigantesco proceso global de movilización productiva, marcado por el signo de la necesidad, ya sea dentro del entramado instrumental eficiente 0 de la adaptación funcional (Arendt, 1995, pp.72-73).

También desde una perspectiva marcadamente aristotélica, Gadamer (2004) ha tratado de resistir la autoapoteosis de la moderna llustración, esto es, las ilusiones de autoconciencia y autocerteza plena, a partir de las cuales se ha forjado el ideal de fundamentación última del conocimiento en la moderna teoría de la ciencia. Y es que, en la teoría científica moderna, el logro de la autocerteza sigue el camino metodológico del cálculo repetible y la coacción controlada, del acoso experimental y la demostración objetivable, que amenaza con recluirnos definitivamente en el universo de la planificación y la técnica (Gadamer, 2004, pp.54-55). En ese sentido, Gadamer reivindica la filosofía práctica aristotélica, ya que, en la deliberación práctica que Aristóteles concibió, no se trata de una simple aplicación metódica de la teoría a 
la práctica, sino que nos guiamos por un ethos compartido, conformado por aquellas finalidades, sentidos normativos y usos comunes, en que ya estamos inmersos en nuestra convivencia cotidiana. Así, pues, la racionalidad de la práctica nos permitiría encontrar una alternativa al saber instrumental y objetivador que caracteriza a la teoría científica y la planificación técnica (Gadamer, 2004, pp.314-315).

De hecho, la distinción aristotélica entre frónesis y tejné explicita la diferencia entre un saber práctico-prudencial referido al agente (a lo que este quiere hacer de sí mismo), de carácter contingente y que delibera lo factible en una situación vital concreta, y, por otra parte, el tipo de conocimiento productivo, enseñable y susceptible de aprendizaje, que surge de la diestra aplicación de un diseño general previo, cuya eficacia no depende de la situación personal, sino tan solo de la previsión objetivadora (Gadamer, 2004, pp.159-160). Al revisar las principales diferencias ente tejné y frónesis, Gadamer nos recuerda que la habilidad productiva de la tejné puede olvidarse, en la medida en que es aprendida, mientras que el saber práctico-político no está sujeto a olvido, pues siempre ya estamos en él. Por lo demás, en el caso de la frónesis, no existe un diseño teórico previo que se ejecute después tal cual; los sentidos normativos y las finalidades compartidas que guían nuestras prácticas se determinan a través de su propia aplicación. Añadamos a esto que -según Gadamer- el conocimiento técnico está restringido a objetivos particulares, para los cuales se determinan medios eficientes, en tanto que el saber práctico afecta al vivir correctamente en general, y requiere del buen consejo para uno mismo. Y es que no se puede determinar a priori la orientación de una vida buena, ni se pueden determinar los medios prácticos al margen de los fines; el saber práctico-prudencial comprende ambos, medios y fines apropiados, siempre en la inmediatez de una situación dada y, por tanto, realizando una auténtica experiencia. Por último, cabe señalar que el saber de la frónesis está referido al agente, pero también a la comprensión de la condición y situación en que los otros con quienes convivimos actúan; así, para el saber práctico resulta crucial tanto la autocomprensión, como la comprensión del otro con quien nos vincula la co-pertenencia a una comunidad, de ese otro con quien eventualmente nos podemos reconciliar (Gadamer, 2003, pp.388395). En suma, la experiencia hermenéutica prefigurada en esta filosofía práctica neo-aristotélica se asocia a una deliberación que, más que consistir en la búsqueda del logro eficiente y objetivable, nos abre a la interpelación del otro y apunta a una 
solidaridad compartida. Como Gadamer argumenta, esto excluye la tentación de resolver nuestras encrucijadas prácticas por medio de la aplicación metódica de la teoría científica o mediante la planificación técnica (Gadamer, 2004, p.165).

Toda esta crítica de la moderna inversión de las relaciones entre contemplación teórica y actividad, así como el cuestionamiento de la subsunción moderna de la praxis -bajo el universo de la aplicación tecnológica y la planificación instrumental-, no consiguen escapar de cierta investidura ideológica de la práctica. En los intentos de rescatar una filosofía práctica neo-aristotélica y el sentido de la actividad práctico-política de la Antigüedad clásica, la autoinvestidura ideológica de la praxis tiene lugar bajo el signo de una doble nostalgia: añoranza romántica y grecófila de una conversación consensual en el seno de tradiciones compartidas, no mancilladas por la movilización tecnológica ni por la cultura de masas; pero, también, nostalgia de una iniciativa política común y de un entendimiento discursivo, en el seno de una polis sin las fracturas ni las divisiones que han caracterizado el ejercicio político en el curso de la revolución democrática moderna. Este rescate ético neoaristotélico se comprende cabalmente en el contexto de un intento de domesticación etificadora (y desnazificación, quizá) de la ontología fundamental y la hermenéutica de la facticidad heideggerianas, en una dirección dialógica e intersubjetiva; se trata de una apuesta llevada a cabo en un momento de reconstrucción ético-política tras la traumática Segunda Guerra Mundial y la catástrofe alemana, por parte de los ahijados intelectuales del filósofo-rector de Friburgo (Wolin, 2003, pp. 29-35).

Por otra parte, ya el relato de una inversión moderna de la jerarquización antigua entre teoría y práctica exhibe los motivos de una lectura ideológica de la reorganización de la división de la labor intelectual y de los saberes prácticos, a través de los procesos de modernización. Y es que no existe una jerarquización moderna; más que de una inversión de una jerarquía preexistente, se trata del establecimiento de una nueva relación de independencia entre los puntos de vista de los saberes, de una interdependencia funcional entre los saberes teóricos y las aplicaciones prácticas, así como de un nuevo nexo instrumental y sistemático en la organización y división del trabajo intelectual. Semejante diferenciación, redistribución y reorganización funcional e instrumental de los saberes y las prácticas no resulta reversible en nombre de una idealizada filosofía de la práctica, nostálgicamente investida de 
una sensatez moral inmanente, de la potencia de una iniciativa política común y de una razonabilidad inherente.

En definitiva, la nostalgia de un sentido práctico tradicional, local y moralmente razonable no resulta menos ideológica que la autocomprensión procedimental de la práctica, que la etificación salvífica de la profesión o que el utopismo de una praxis sobrecargada de expectativas mesiánicas. Todas estas modalidades ideológicas de autocomprensión de las actividades humanas y de su relación con la teoría parecen presuponer un marco compartido -típicamente moderno, pese a su investidura nostálgica sacralizada o al mesianismo utópico-, que consagra la puesta en obra, la efectualidad, la operatividad y el oficio. A pesar de encerrar cierta fascinación por lo originario y una ontologización de la autocomprensión moderna, resulta reveladora la arqueología del oficio que Agamben propone en Opus Dei:

En este sentido, el concepto de oficio significó una transformación decisiva de las categorías de la ontología y de la praxis, cuya importancia aún debemos medir. En el oficio, ser y praxis, lo que el hombre hace y lo que el hombre es, entran en una zona de indistinción, en la que el ser se resuelve en sus efectos prácticos $y$, con una perfecta circularidad, es lo que debe (ser) y debe (ser) lo que es. En este sentido, la operatividad y la efectualidad definen el paradigma ontológico que, en el curso de un proceso secular, sustituyó al de la filosofía clásica: (...) tanto del ser como del obrar hoy no tenemos otra representación diferente a la de la efectualidad. Solo es real lo que es efectivo $y$, como tal, gobernable y eficaz: a tal punto, bajo las modestas vestiduras del funcionario o bajo las gloriosas del sacerdote, el oficio cambió de principio a fin tanto las reglas de la filosofía primera como las de la ética. (Agamben, 2013, p. 15)

En vez de rastrear arqueológicamente cierto trasfondo originario del oficio y la operatividad modernos, en este artículo solo hemos tratado de explicitar el reverso ideológico de las formas de autocomprensión de la práctica como procedimiento, profesión o praxis; esto es, el velado sistemático, el disfraz nostálgico, la neutralización procedimental y la obliteración mesiánica de las complejas relaciones de exterioridad e interdependencia entre teoría y praxis, tanto en los sistemas sociales como en el mundo de vida contemporáneo. 


\section{Referencias bibliográficas}

Agamben, G. (2013). Opus Dei. Arqueología del oficio. Valencia: Pre-Textos.

Althusser, L. (1974). Para leer El Capital. México D. F.: Siglo XXI.

Arendt, H. (1995). De la historia a la acción. Barcelona: Paidós.

Arendt, H. (2005). La condición humana. Barcelona: Paidós.

Aristófanes (1984). Comedias. Barcelona: Bruguera.

Aristóteles (2000). Ética Nicomáquea. Madrid: Gredos.

Bourdieu, P. (1999). Meditaciones pascalianas. Barcelona: Anagrama.

Dewey, J. (1986). La reconstrucción de la filosofía. Barcelona: Planeta-Agostini.

Dewey, J. (2000). Qué entiende el pragmatismo por «práctico». En La miseria de la epistemología. Ensayos de pragmatismo (pp. 81-98). Madrid: Biblioteca Nueva.

Diógenes Laercio (1887). Vidas, opiniones y sentencias de los filósofos más ilustres. Tomo I. Madrid: Luis Navarro editor.

Dumont, L. (1987). Ensayos sobre el individualismo. Madrid: Alianza Editorial.

Gadamer, H. G. (1993). Elogio de la teoría. Barcelona: Península.

Gadamer, H. G. (2003). Verdad y método I. Salamanca: Ediciones Sígueme.

Gadamer, H. G. (2004). Verdad y método II. Salamanca: Ediciones Sígueme.

Gouldner, A. W. (1983). Los dos marxismos. Madrid: Alianza Editorial.

Gramsci, A. (1986). Introducción a la filosofía de la praxis. Barcelona: Planeta-Agostini. Hadot, P. (2006). Ejercicios espirituales y filosofía antigua. Madrid: Siruela.

Havelock, E. A. (2002). Prefacio a Platón. Madrid: Antonio Machado Libros.

Heidegger, M. (1960). La época de la imagen del mundo. En Sendas perdidas (pp. 68-99). Buenos Aires: Losada.

Heidegger, M. (1997). Filosofía, ciencia y técnica. Santiago de Chile: Editorial Universitaria.

Horkheimer, M. (1969). Crítica de la razón instrumental. Buenos Aires: Editorial Sur.

Horkheimer, M. (2003). Teoría tradicional y teoría crítica. En Teoría crítica (pp. 223-271). Buenos Aires: Amorrortu. 
Husserl, E. (1998). Invitación a la fenomenología. Barcelona: Paidós.

Jaeger, W. (1992). Aristóteles. México, D. F.: Fondo de Cultura Económica.

James, W. (1984). Pragmatismo. Madrid: Sarpe.

Jonas, H. (1995). El principio de responsabilidad. Ensayo de una ética para la civilización tecnológica. Barcelona: Herder.

Jonas, H. (2000). Acerca del uso práctico de la teoría. En El principio vida (pp. 253-277). Valladolid: Trotta.

Kennedy, G. A. (1997). The Cambridge History of Literary Criticism: Classical Criticism. Volume I. New York: Cambridge University Press.

Labriola, A. (1969). Socialismo y filosofía. Madrid: Alianza Editorial.

Luciano de Samosata (1976). Diálogos de tendencia cínica. Madrid: Editora Nacional.

Lloyd, G. E. R. (1987). Polaridad y analogía. Madrid: Taurus.

Marx, K. (1985). Tesis sobre Feuerbach. En Trabajo asalariado y capital (pp. 33-36). Barcelona: Planeta-Agostini.

Menand, L. (2002). El club de los metafísicos. Historia de las ideas en los Estados Unidos. Barcelona: Destino.

Platón (2007a). Teeteto. En Diálogos V (pp. 133-311). Barcelona: RBA.

Platón (2007b). Político. En Diálogos V (pp. 473-605). Barcelona: RBA.

Reale, G. (1996). La sabiduría antigua. Barcelona: Herder.

Toulmin, S. (2001). Cosmópolis. El trasfondo de la modernidad. Barcelona: Península.

Weber, M. (1984). La ética protestante y el espíritu del capitalismo. Madrid: Sarpe.

Wilson Nightingale, A. (2004). Spectacles of Truth in Classical Greek Philosophy. Theoria in its Cultural Context. New York: Cambridge University Press.

Wolin, R. (2003). Los hijos de Heidegger. Madrid: Cátedra. 